\title{
Painting Aesthetics and Educational Enlightenment of Ren Renfa in Yuan Dynasty
}

\author{
Xiaoli Wu \\ Art college of xi'an university, 710065
}

Keyword: Character Creation; Realistic Analysis; Independent Creation

\begin{abstract}
Ren Renfa lives in Yuan Dynasty which two dynasties changed, but he wins the later admiration through the water conservancy projects and paintings that surpassed the era. In the balance between reality and ideal, he finds the painting as a media to hit reality and does not avoid social contradictions. His painting style is profound and elegant. Ren Renfa is a water official and his painting perspective and methods are different from other painters, so he is not known to everyone. In the teaching and creating class, we draw on the creative form and the painting style of Ren Renfa in Yuan Dynasty to find a new way of learning for the students' graduation creative course.
\end{abstract}

\section{The Balance between Reality and Ideal - the Seventies of 13th Century that is the Chaos of Times and the Anxiety of Life}

He was born in a period which has collision of the two nationalities full with big changes and intersection. Mongolia that rapid developed on grassland conquered the Asia-Europe continent. And then Kublai prepared for the strategic layout of the Southern Song Dynasty that period is very turbulent, which was the period Ren Renfa born in. According to historical evidence, he had painted "Xi Chun Tian Ma" and "Wo Wa Tian Ma" for the Song Renzong and he was 20 years old.

"Chu Yu Tu" was finished at his 27 years old. The whole painting consists of three persons and four horses. The horse in the middle of painting with a gorgeous jade eating grass, the other horse looks at distance thoughtfully. There are three parts of "Jiu Ma Tu". In the first part, the two horses were led out by person. In the second part, two horses drink water. The third part depicts the four horses in the trough, two of which are bowed to the grass and the other two are raised.

The horse wearing a gorgeous jade bowed to graze and another one with its head held far away and want to break free of custody. These two actions reflects the inner contradictions and conflicts of Ren Renfa. He had some confusions and questions at his 27 years old. The picture attempts to find the future and reality from the past and the vitality. The seventies of the 13th century was a period that is a intersection of history and the fate of the individual. Ren Renfa expresses his spiritual demands in the field of painting with the narrative style and records the loss of life with a contradictory collision of emotional catharsis.

Kublai Khan established Yuan Dynasty. There is no Han nationality taking over political rights and political vocabulary is Mongolian language, which means that the right avoids the Han nationality. The Southern Song Dynasty survivors immediately left away from politics and created a literati style to express the spirit with ink, which create a freehand brushwork of Chinese painting. Participants include senior officials, squire, hermit, mad and monk. The painting has emerged a new situation of vigorous and active. Brush painting finds the "Ink" complex, so the ink painting world occupied the history of the Yuan Dynasty painting 97 years. This short connection and exchange make the spiritual demands of painting become mainstream. Ren Renfa creation style is formed by this trend of thought. He widely accepts thought and his painting techniques complete gradually, such as landscape, flowers and birds, people, calligraphy, pommel horse. At the same time, he learns from the water and land painting and palace style, which makes his paintings rigorous and carved. Besides, he is also good at dealing with the coordination and interaction of characters and scene, known as a versatile painter. 


\section{Dual Identity in Court - Describe the Reality rather than Painting Entertainment}

Southern Song Dynasty collapsed in 1279 year at Guangdong cliff. Ren Renfa was 27 years old and to see You Xian. You Xian liked him and put him in an important position. Ren Renfa made good at dealing with affairs and gradually showed the pattern in the government, so the final official to the military are water division deputy director.

In the social system, facing the earth, he is a downright official, which is the identity from the reality. The other is the identity of his personal dimension, the artist. In the field of art, he is the suitor of the local culture and his painting has a very clear position of the Han culture, around the history of Chinese culture, value orientation for the content. This is a trend, which all the Han nationality is collective to the past throughout the Mongolian period. Zhao Mengfu who led by the literati class advocated "retro". He said that if there is no ancient meaning in painting, it is not useful. Ren Renfa undertook the "ancient meaning", the characters in the painting wear "Tang" clothes, which is a nostalgia or admiration for the past a period of great history and is full of retrospective emotions for the loss of the prosperous era. Ren Renfa's painting is a way of seeking national identity under the premise of "ancient meaning". This way is very effective, which make him subtle and introverted become the spokesperson of the Han culture. In the battle of two nationalities, the intention and the form of the painting are also in the battle and he is struggling to find a great balance in the painting.

His artistic values are different from Zhao Mengfu. Zhao Mengfu clearly stressed that "reduce content" in the painting, while Ren Renfa obviously is not like this. In the painting, Ren Renfa often uses "reality" as the starting point and does not avoid social problems, even expressed the critical of reality in the painting.

There are two horses side by side in the "Two Horse Painting". The right side is a brown and white horse, fat and no bound, looking pampered and proudly. The left side is a brown and thin horse, head down and skinny, tail curled up and exhausted. Ren Renfa wrote a sentence about the fat and thin horse on the painting. There are two kinds of people in the court. One kind work for people and the other kind only care about themselves.

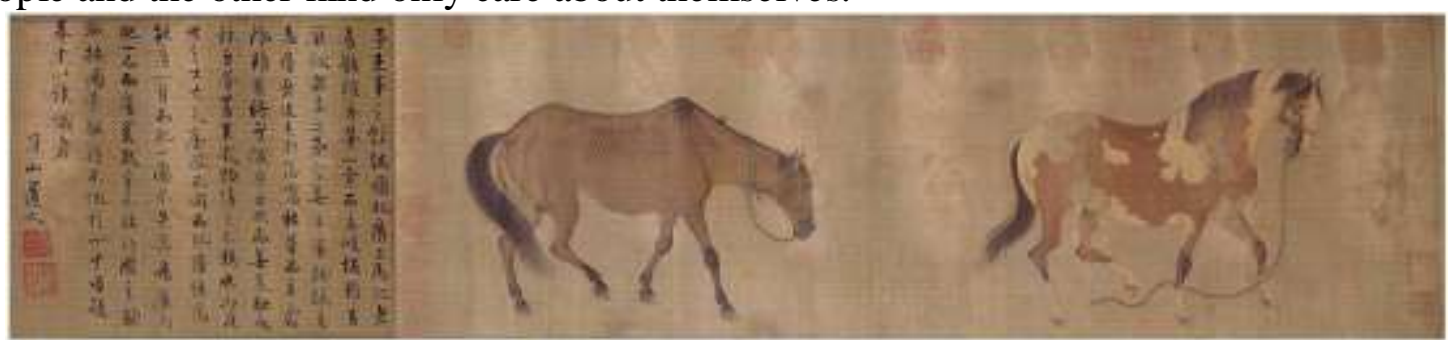

Ren Renfa faces the people's livelihood and the officialdom directly, clearly exposes the official corruption and darkness and deep concerns about the people's livelihood. At the same time, Zhao Mengfu's paintings show entertainment life scene in the "ancient meaning" and describe characters and horses revel in the pastoral scenery, leisurely relaxed, carved and colorful. The painting level only stay in the form, just as what he advocated "reduce content". Zhao Mengfu was born in the royal family. His noble identity makes him always in the spire of society, which determines him can not really go to the people's livelihood and vision. Therefore, it is inevitable that his painting can only stay in the "joy" level. Ren Renfa is different. He has a life of multi-dimensional survival experience and experience, walking in the middle of affairs and people's livelihood. His situation revealed in the context of painting. His painting is clearly not to impress the appreciation and only to express criticism. The description of "reality" in his painting put the complexity of the arts to the viewer and the skills is hidden in the huge social issues.

Painting "Five King Drunk" depicts Tang Ming Huang Li Longji and his four brothers travel and drunk riding back before he began to reign. In terms of character design, there are five princes and four attendants in the painting. Among them, Li Longji wears a deep red dress and behind him is Song Wang Li Xian, followed by Qi Wang, Xue Wang, Shen Wang. This painting has a deep implication, which praise affectionateness between brothers. According to the record of "Ming Huang Miscellany" wrote by Zheng Chuhai, five princes had a good relationship when they were 
young. According to the ancient monarchy, the successor of Tang Ruizong should be entourage eldest son Song Wang Li Xian. However, Rui Zong want Li Longji to be the Prince as he is meritorious and outstanding, but it is not ritual. Therefore, Song Wang abandoned Prince so that the Prince was Li Longji.

The concept and layout of this painting is clever. The protagonist Li Longji is the first position in the painting, not exposed face. Meanwhile, Li Xian who is the second slightly drunk and sits dignified, thoughtfully. Li Xian took the initiative to the throne to the younger brother Li Longji. This painting want to admonish Yuan Renzong, which was painted at his tenure. When Yuan Wusong died, the throne was passed to Yuan Renzong and he promised to pass the throne to the son of Wu Zong, but he broke his words and the throne was passed to his own son. After Wu Zong died, this throne dispute caused a few decades of melee.

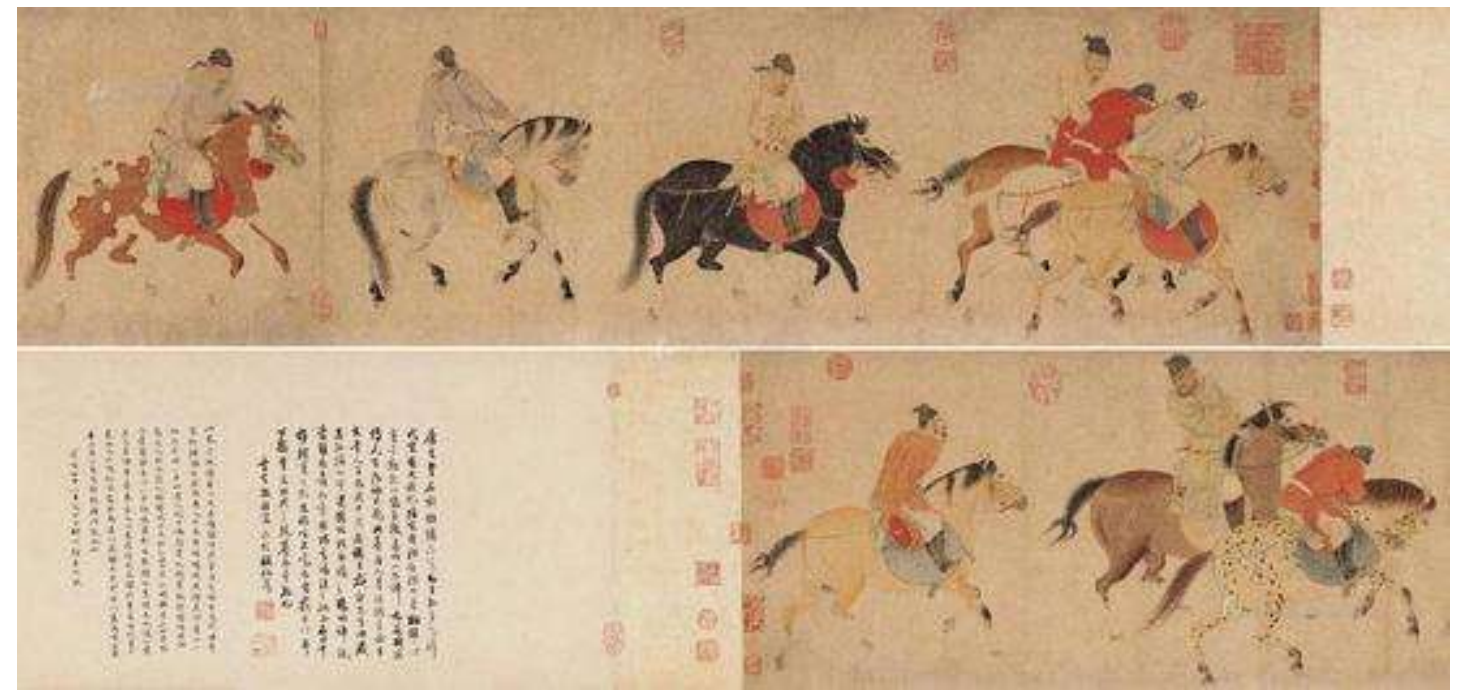

Ren Renfa's paintings are saying today by the ancient. His painting is always behind major historical event as he rarely takes a cold attitude towards the world. He objectively performed his political views using the art form of the long brushwork, ancient metaphor of the literature style, politician's rational, artisan-like creative passion and vivid and pure skills. The realistic reason is distinguished from the painter's individualism, and his paintings are closely related to the particular historical period. The history of painting makes his works in a particular historical era full of conflict and contradiction. This pursuit of the narrative is from his rich literary heritage. The literary occupies an important part of his painting creation, but his creation is not only illustrative. His creative attitude towards the creation is sincere and serious. The identity of political official and artist makes him a unique landscape in a particular historical period.

\section{Realism and Idealism Coexist}

If the Ren Renfa's painting is completely attributed to the realistic painting, it seems easy to cause misunderstanding, but the accuracy of the shape and the authenticity of the event seems to be based on "realistic" realism. The picture of the plot has a literary story and dramatic. Although the picture is still, the characters in the story have action. Ren Renfa made sure to use meticulous, subtle brushwork techniques to the viewer with a sense of view. Although his freehand brushwork was quite high, he gave up. He still used a long time-consuming brushwork technique that would slowly bloom. His rigorous request makes the expression within the picture perfect, so that the survival of the 21 works can be used "beautiful" to describe. The size of "Xue Mei Shu Wu Painting " is $143 \times 78 \mathrm{~cm}$, which confessed his affection. In the deep snow-capped mountains, a quiet hut is away from the hustle and bustle of the earth. There is a literatus reading. The painting meticulously depicts the scene of all the picture and it is quiet as a "dream" territory, which maps out the hustle and bustle of outside world. 1279-1311, Mongolian continue to campaign in these 32 years. Slightly 
settled, there also broke the emperor struggle and no one took care the water remediation of eastern part of the Mongolian, so that people suffer every year. He has also been looking for a comfortable dream - to go back to school, painting, to escape the world, quiet life, to establish their own cultural ideals. Finally, he began to build water conservancy and completed ten important water conservancy system renovation projects in the eastern region, exhausted his rest of life. Ren Renfa left a total of 21 paintings in the world. Water conservancy books are "Huang Du Down" and "Zhejiang West Water Conversation" ten volumes. Literary and artistic works are "Book History Summary" "Painting and Calligraphy History" "Lian Shui Hua Zheng Lu" and " Hai Shang Mo Lin" and so on.

He completed several times the efforts of other people's life in his 74 years of life. His paintings have many quiet ideals and calm demands, which transforms his calm demands on the earth. His painting is not only involved in the reality but also touched the Mongolian sensitive political nerve, that is, the benefit of the people and the completion of the ideal of the Han culture of national complex, with a balance of realistic and ideal painting. His paintings avoid the mere formality and the unique painting perspective is more embedded in his ideal. These paintings map the height of the spiritual dimension of his life, such as "Yin Zhong Ba Xian" "Heng Qin Gao Shi " "Qiu Lin Shi You" and "Qin Qi Shu Hua". Reality and ideal is difficult to determine which one he is more inclined to. He is not entirely a realistic painter and also has a personal spiritual ideal.

\section{Educational Enlightenment}

These are new topics how to hit the reality theme and create artistic conception in the students figure painting. From painting copy to independent creation, it must go through research and analysis, learning and independent thinking, which is a process that gradually mature. How to guide students to draw a good creation, teachers need to communicate with students and adjust the creative ideas and direction. Ren Renfa provides the exploration needs for students who need to draw realistic themes, especially for those who like the realistic themes of painting.

\section{Reference}

[1] L. Ye. "Outline of Chinese Aesthetics History", Shanghai People's Press, 1985 edition.

[2] H. Z. Hong. "Comparison of Chinese and Western Paintings", Hebei Fine Arts Press, 2000 edition.

[3] S. J. Li. "Expression of Chinese Artistic Paintings ", "Journal of Shandong University", 2009 (5).

[4] Y. M. Qiu. "The Formation and Development of Chinese Ancient Artistic Conception", "Journal of Kaifeng Institute of Education", 2003 (6).

[5] F. S. Li. History of Chinese Art [M]. Beijing: Higher Education Press, 2002.

[6] M. Z. Guo. Chinese Painting Art Appreciation [M]. Beijing: China Textile Press, 1998.

[7] K. R. Li. Li Keran Talk about Art [M]. Beijing: People's Fine Arts Publishing House, 2000.

[8] X. Y. Guo. On Art [M]. Beijing: Culture and Art Press, 2001.

[9] S. C. Xu. Painting History of Song Dynasty [M]. Beijing: People's Fine Arts Press, 2000.

[10] W. Zheng. History of Chinese Painting [M]. Beijing: Beijing Press, 2004.

[11] Y. N. Xue. Chinese Art - Five Dynasties to Song and Yuan Dynasty[M]. Beijing: China Renmin University Press, 2004.

[12] C. L. Wang. The Transmutation of the Aesthetic Features of the Landscape Paintings in the Song Dynasty [J]. Fine Arts Guide, 2000-01.

[13] J. P. Zheng. Simple and Deep Beauty - The Change of Language Form of Traditional Landscape Painting in Song Dynasty [J]. Fine Arts, 2007.

[14]D. S. Zhang. Chinese Art Appreciation [M]. Hangzhou: Zhejiang Fine Arts Press, 2005.

[15] S. L. Li. Chinese Art History [M]. Hohhot: Inner Mongolia People's Press, 2006. 